\title{
Studies on Aroma Gene and its Application in Rice Genetics and Breeding
}

\author{
Bo Peng ${ }^{1}$, Yu-Han Zuo ${ }^{1}$, Yan-Lin Hao ${ }^{1}$, Juan Peng ${ }^{2}$, Dong-Yan Kong ${ }^{1}$, Yu Peng $^{3}$, Tondi-Yacouba Nassirou ${ }^{4}$, \\ Lu-Lu He ${ }^{1}$, Yan-Fang Sun ${ }^{1}$, Lin Liu ${ }^{3}$, Rui-Hua Pang ${ }^{1}$, Ya-Xin Chen ${ }^{1}$, Jin-Tiao Li ${ }^{1}$, Qi-Ying Zhou ${ }^{1}$, Bin Duan ${ }^{5}$ \\ Xiao-Hua Song ${ }^{5}$, Shi-Zhi Song ${ }^{5} \&$ Hong-Yu Yuan ${ }^{1}$ \\ ${ }^{1}$ College of Life Sciences and Institute for Conservation and Utilization of Agro-bioresources in Dabie \\ Mountains, Xinyang Normal University, Xinyang 464000, China \\ ${ }^{2}$ Xinyang Station of Plant Protection and Inspection, Xinyang 464000, China \\ ${ }^{3}$ School of Science and Technology, Xinyang University, Xinyang 464000, China \\ ${ }^{4}$ Plate Forme Agroécologique Multi Acteurs Raya Karkara Du Niger, BP: 11271, Niamey, Niger \\ ${ }^{5}$ Xinyang Academy of Agricultural Science, Xinyang 464000, China \\ Correspondence: Bo Peng, College of Life Sciences and Institute for Conservation and Utilization of \\ Agro-bioresources in Dabie Mountains, Xinyang Normal University, Xinyang 464000, China. E-mail: \\ pengbo@xynu.edu.cn \\ Tondi-Yacouba Nassirou, Plate Forme Agroécologique Multi Acteurs Raya Karkara Du Niger, BP: 11271, \\ Niamey, Niger. E-mail: tnassirou2009@gmail.com \\ Xiao-Hua Song, Xinyang Academy of Agricultural Science, Xinyang 464000, China. E-mail: \\ fairysheepsong@sina.com \\ Hong-Yu Yuan, College of Life Sciences and Institute for Conservation and Utilization of Agro-bioresources in \\ Dabie Mountains, Xinyang Normal University, Xinyang 464000, China. E-mail: yhongyu92@163.com
}

Received: April 30, 2018

doi:10.5539/jps.v7n2p29
Accepted: May 25, 2018 Online Published: June 28, 2018

URL: https://doi.org/10.5539/jps.v7n2p29

\begin{abstract}
Rice (Oryza sativa L.) is one of the most important food crops in the world, and the staple food for more than half of the world's population. Along with the sustained development of living standards, people's demand for high quality rice is increasing. As one of the types of cultivated rice, aromatic rice is preferred by most of the consumers because of its agreeable scent. With the rapid development of rice functional genomics and sequencing technology, great progress has been made in understanding the aroma gene in rice, and a series of functional markers has been developed for screening the aroma gene and breeding new rice varieties in recent years. This paper mainly reviews the progress in the genetic basis, gene function and regulation of the aroma gene, and the application of aroma gene functional markers in the genetic improvement and breeding of aromatic rice. Thus, it provides important references for the cultivation of new varieties of aromatic rice.
\end{abstract}

Keywords: Aroma gene, application, genetic breeding, aromatic rice

\section{Introduction}

Rice (Oryza sativa L.) is one of the most important food crops in the world, providing about $25 \%$ of energy to more than 3 billion people (Tian et al., 2009; Peng et al., 2017a). For most Southeast Asians, rice supplies more than 35\% of their energy requirement (Peng et al, 2014a; Li et al., 2015). Fragrance in rice counts as one of its most important eating quality traits (Tang et al. 2009). These varieties are regarded as the rare types in the market (Bradbury et al., 2005a; Zhao et al, 2009; Myint et al., 2012; Daygon et al., 2016). The traditional rice varieties with poor resistance and low yield are difficult to be popularized in large areas (Bai et al, 2009; Du et al, 2009). However, the market price of aromatic rice is higher; and its demand has increased significantly in recent years (Shao et al., 2013; Shi et al., 2014; Peng et al, 2016a). Consequently the aroma gene research and its application in genetic breeding have been widely investigated by geneticists and rice breeders.

In the second half of the $20^{\text {th }}$ century, Although, the rice yield was significantly increased, rice production has been stagnating since the 1980s. At present, different factors such as environmental pollution, water shortage and 
frequent occurrence of extreme weather affect not only the growth and final grain yield of rice, but also affect seriously its quality (Stocker et al., 2013; Zhao and Fitzgerald, 2013; Goufo et al., 2014; Halford et al., 2014). With the continuous growth of the world population and the steady improvement of living standard, traditional rice breeding has been unable to meet the strong demand for high-quality and high-yield rice (Peng et al, 2016b). Finding new breeding strategies and methods (such as marker assisted selection, whole genome breeding, molecular design breeding and transgenic breeding) will make up for the shortage of traditional rice breeding so as to achieve breakthroughs in rice yield and synchronous improvement of rice quality. Great progresses have been made in the genetics and breeding of aromatic rice, including the isolation and cloning of aroma genes, and functional analysis (Shan et al., 2013, 2015; He and Park et al., 2015; Yan et al., 2015). At the same time, new technologies and breeding strategies have begun to be applied in the breeding of aromatic rice (Shan et al., 2015). Therefore, to clarify the molecular genetic mechanism of aroma gene, and new breeding strategies and methods such as molecular marker-assisted selection breeding, all of these will provide important information for the cultivation of new varieties of aromatic rice.

There are more than 200 kinds of volatile substances in rice (Mahattanatawee and Rouseff, 2014; He and Park, 2015), of which 2-acetyl-1-pyrroline (2-AP) is one of the main volatile substances in aromatic rice (Mathure et al., 2014; Mahattanatawee and Rouseff, 2014). At present, numerous methods have been used to detect the aroma of rice materials. Among them, the chewing method and $\mathrm{KOH}$ method are the most commonly used in the traditional rice breeding process (Bradbury et al., 2005b; Liu et al, 2014; Yan et al, 2015). However, these two methods mainly rely on human senses to determine the fragrance, which is poor in accuracy and is difficult to be employed in the screening and breeding of new varieties of rice. Therefore, how to identify scent in aromatic rice simply, accurately and quickly has always been one of the problems that rice breeders urgently need to solve (Yan et al., 2015). Although the genetic basis of aroma in aromatic rice is complex, most researchers think that the fragrance is controlled by a single recessive gene $(f g r)$, on the eighth chromosome of rice genome, which is one gene closely related to the fragrance, and the $f g r$ gene has been isolated and cloned at present (Bradbury et al., 2005a; Chen et al., 2006; Chen et al., 2008). Further studies have revealed that the $f g r$ gene encoding betaine aldehyde dehydrogenase (Badh2). Inhibits the expression of $f g r$ gene, knockout $f g r$ gene or $f g r$ gene mutation, which will cause the deletion of Badh2 enzyme function, cause the increase of 2-AP precursor substance, and then accumulate the 2-AP to produce the fragrance in rice grain (Niu et al., 2008; Shan et al., 2013). However, although important advances have been made in the biochemical metabolic pathways of rice aroma gene, further research is needed on the allelic variation of aroma gene, the number of gene controlling aroma, and the application of aroma genes in the cultivation of new rice varieties. In this paper, we have reviewed the recent progress made in the study of aroma gene in rice, and the development and application of functional markers of aroma gene, which will provide important references for the cultivation of new varieties of high quality aromatic rice.

\section{Genetic Basis of Rice Aroma Gene}

Aromatic rice has been favored by the consumers, because it has a unique aroma in rice, at home and abroad (Kovach et al., 2009; Shan et al., 2015). In addition, the genetic basis of rice aroma gene has also made great progress. Indeed, the recessive gene that controls fragrance was located on the chromosome 8 in rice, in 1992 by researchers and they found that the genetic distance between aroma gene and the molecular marker RG28 was $4.5 \mathrm{cM}$ (Ahn et al., 1992). Since then, a number of research teams also detected the recessive gene controlling rice fragrance using different genetic populations and different types of molecular markers near the RG28 (Jin et al., 1995, 1996; Lorieux et al., 1996; Dong et al., 2001a, 2001b). For instance, Zhang Tao et al. (2008) used aromatic rice and indica non-fragrant rice as experimental materials, and located the aroma gene in the region of approximately $252 \mathrm{~kb}$ between $20175367 \mathrm{bp}-20386172 \mathrm{bp}$ on chromosome 8. Similarly, Wanchana et al (2005) had located the aroma gene $f g r$ between the molecular markers RM223 and RM342. And further studies revealed that the difference between aromatic rice and non-aromatic rice was due to the two molecular markers on the gene encoding betaine dehydrogenase (BADH2).

There was a significant difference in the sequence of Badh2 gene between the aromatic rice and the nonaromatic rice after sequencing the $f g r$ region. Indeed, after map-based cloning and sequencing of the $f g r$ region, it was found that there was a significant difference in the sequence of Badh2 gene between aromatic rice and non-aromatic rice, and there was a mutation in aromatic rice in the 7th exon region of Badh2 gene, which leading to the loss function of Badh2 protein. Therefore, Badh2 gene is likely linked to $f g r$ gene, which control the rice fragrance (Bradbury et al., 2005a). In order to verify the function of the Badh2 gene, 3 candidate genes in the $f g r$ region were simultaneously transformed into a complementary transformation experiment. The results showed that the fragrance of the two candidate genes, $C a h$ and $M c c c 2$, did not change significantly in the rice before or 
after the transgene, however, in the transgenic single plant of the Badh2 gene, the fragrance was changed obviously. Though, when using RNAi technology to inhibit the expression of Badh2 gene, that could also produce fragrance for non-fragrance in rice. These results might confirm that the Badh2 gene is a recessive gene that controls grain fragrance in rice (Chen et al., 2006, 2008, 2012; Niu et al., 2008).

The full length of Badh2 gene is 1509 bp, which contains 15 exons and 14 introns, encoding 503 amino acids (Chen et al., 2008; Shan et al., 2015). Comparing the aromatic rice and non-aromatic rice, there were many kinds of mutations in Badh2 gene among different rice varieties. For example, in aromatic rice varieties, it is common that there is an 8 bp deletion and 3 single nucleotide polymorphism sites (SNPs) in the 7th exon of Badh2 gene (Bradbury et al., 2005a). In different varieties of aromatic rice, there is a 7 bp deletion in exon 2 of the Badh2 gene and a 803 bp deletion between exon 4 and exon 5 (Shi et al., 2008; Kovach Et al., 2009; Shao et al., 2011), and there are variation sites in exons 1, 10, 13 and 14 (Shi et al., 2008; Amarawathi et al., 2008; Kovach et al., 2009). Further studies have found that the splice sites of the first exons and first introns of the Badh2 gene, the promoter region, and the 5 'UTR region also have insertion, deletion, or single nucleotide mutation sites (Shao et al., 2011, 2013; Shi et al., 2014; Ootsuka et al., 2014). The difference in aroma of rice grain is largely determined by allelic variation of the Badh2 gene. The aroma related rice varieties often include the deletion of seventh exon 8 bp and 3 SNPs, or the deletion of 7 bp in the second exon (Shi et al., 2008; Shao et al., 2013). Therefore, when Badh2 gene is mutated in coding region or regulatory region, it could produce betaine dehydrogenase which has no biological activity, and cause rice to produce fragrance.

In order to further analyze the genetic characteristics of the rice aroma gene, the whole genome analysis of the aroma gene of the Barth Marty aromatic rice was analyzed. It was found that in the genome of the aromatic rice, there were 2 quantitative trait loci (QTLs) that control the fragrance of rice grain in addition to the Badh2 gene on the eighth chromosome. They were located on the third and fourth chromosome of rice (Amarawathi et al., 2008). The quantitative trait loci on the fourth chromosome could be related to the Badhl gene, while the Badhl and Badh2 belong to the homologous gene, and the Badhl gene in rice was also highly homologous to the Badhl in the sorghum (Sorghum Bicolor) and the barley (Hordeum Vulgare) genome (Bradbury et al.2005a, 2008). Moreover, recently, it has been found that the Badhl gene has a significant positive correlation with salt tolerance in rice at the germination stage (He et al., 2015). The mutation of the Badhl gene was also linked to the aroma in rice grain, but the effect is far less than the Badh2 gene (Amarawathi et al., 2008). Therefore, the relationship between the Badhl gene and fragrance in rice grain need further study.

In different rice varieties, 18 bp deletion and 3 single nucleotide polymorphisms were found in the seventh exon of the Badh2 gene, and the same mutation occurred in the seventh exon of the Badh2 gene in the non-aromatic rice varieties (Fitzgerald et al., 2008). In another hand, the analysis of 280 wild rice varieties and 242 cultivated rice varieties from 38 countries and regions in Asia showed that there were 8 kinds of haplotypes without functional activity in Badh2 gene. The Badh2 gene derived from rice material similar to the genetic background of japonica rice. The aroma gene in the existing indica aromatic rice might be imported from japonica rice varieties and constantly selected by artificial selection (Kovach et al., 2009). Studying wild rice varieties, the research group found that there was also a type of Badh2 gene with seventh exons in the common wild rice varieties in Asia, and the Badh2 gene of these missing or mutant types were relatively less in wild rice varieties (Prathepha, 2009), and they could not be translated into normal translation, but they could lead to the Badh2 gene. It performs efficient transcription and translation (Chen et al., 2008), and then inhibits the fragrance in rice grain. Previous studies showed that the aroma gene in the existing cultivated rice varieties originated from the earliest wild rice varieties, followed by a long period of artificial selection and domestication (Kovach et al., 2009; Prathepha, 2009; Shao et al., 2013; He et al., 2015). In the process of artificial selection and domestication, aroma gene is likely to produce a range of variations, leading to a large difference in the conclusion of different research groups. In regard of this fact, most researchers believed that the fragrance inheritance is controlled by a single recessive gene (Shao et al., 2013; He et al., 2015), while some others believed that the aroma of aromatic rice is inherited from a multi recessive basis. However, according to the decision resulting from studies such as (Tsuzuki and Shimokawa, 1990), some scholars believed that fragrant inheritance is controlled by some main-effective genes and micro-effective genes (Xu and Mo, 1995), and several QTLs controlling the fragrant in rice grain (Lorieux et al., 1996; Amarawathi et al., 2008). In conclusion, the genetic basis of rice aroma gene is complex, and the gene controlling rice fragrance are 1 pair, or 2 to 4 pairs or more, all of these may be due to: (1) The different genetic basis of different fragrant types (such as popcorn, jasmine, violet and hickory) varieties; (2) There are interactions between aroma genes and various environmental factors (light, temperature and soil fertility); However, in the present the diversity of the fragrant components in rice grain, the methods and techniques for identification of different types of fragrant still not perfect yet. 


\section{Function and Regulation of Rice Aroma Genes}

Although the aroma of rice grain is made up of a variety of volatile substances, 2-AP is currently the main aromatic compound (Paule and Powers, 1989; Kovach et al., 2009), and 2-AP has a lower odor threshold, easily soluble in ethanol and ether. The aromatic rice from India and Thailand markets belong to indica aromatic rice varieties, and the 2-AP provides for its unique flavor. Numerous previous studies showed that the Badh2 gene mutation on the eighth chromosome could produce fragrant, while the Badh2 protein encoded by Badh2 in nonaromatic rice had the activity of betaine dehydrogenase. The activity of betaine dehydrogenase was lost in the mutation type, and the accumulation of 2-AP resulted in the production fragrant in rice grain (Kovach et al., 2009; He and Park, 2015; Shan et al., 2015). Further studies have found that there are multiple transcriptional starting sites in the Badh2 gene. In non-aromatic rice, although the Badh2 has 3 transcriptional transcripts with different lengths, only the $B a d h 2$ gene transcriptional level with a total length of $1509 \mathrm{bp}$ is higher than the other alleles. In the aromatic rice varieties, the main transcriptional starting site is located at downstream of the Badh2 gene initiation codon, and the transcription of the Badh2 gene is severely inhibited in the aromatic rice varieties (Chen et al., 2008). So far, although the loss of Badh2 gene function has been proved to lead to the production of 2-AP, how does Badh2 protein regulate the synthesis process of 2-AP? 2-AP biosynthesis pathway and related regulatory network and regulatory mechanism are not clear in the current status.

In view of 2-AP biosynthesis pathway and its regulatory network, different research groups have carried out a number of related researches. In non-aromatic rice varieties, the activity of betaine aldehyde dehydrogenase encoded by dominant Badh2 allele is highly inhibited, and 2-AP synthesis is inhibited. In aromatic rice varieties, two recessive alleles (Badh2-E2 and Badh2-E7) of Badh2 are not capable of producing active betaine aldehyde dehydrogenase, which could induce the formation of 2-AP (Chen et al., 2008). The results of radioisotope tracer experiments show that proline is one of the precursors of 2-AP biosynthesis, which provides nitrogen source for 2-AP, and the formation of 2-AP has a significant positive correlation with the accumulation of proline (Yoshihashi et al., 2002). The results also showed that the precursor of gamma aminobutyric aldehyde (gamma -Aminobutyraldehyde, GABald) was synthesized by proline and ornithine, through the intermediate 1-pyrroline (delta 1-P), then the 2-acetyl-1-pyrrolinewas synthesized finally (Schieberle, 1990). Betaine aldehyde dehydrogenase not only catalyzed 3-aminopropionic (A-Pald), two methyl sulphur propionic (DMSPald) and sugar beet (Betald), but also catalyzed the synthesis of 2-AP precursors gamma aminobutyral (GABald) (Trossat et al., 1997; Chen et al., 2008; 2015). In rice, Badh2 protein could catalyze gamma aminobutyric acid to be gamma aminobutyric acid (gamma-Aminobutyric acid, GABA) (Shan et al., 2015), and the content of GABA in non-aromatic rice varieties is much higher than that in aromatic rice. In view of the biological function of betaine aldehyde dehydrogenase, there is a big discrepancy between the results obtained by different research groups. It is considered that betaine aldehyde dehydrogenase can inhibit the synthesis of 2-acetyl-1-pyrrolidine (Chen et al., 2008), and the results showed that betaine aldehyde dehydrogenase was involved in the decomposition of 2-acetyl-1-pyrrolidine (Trossat et al., 1997), and researchers believed that there was a competitive relationship between the precursor of betaine aldehyde dehydrogenase and 2-acetyl-1-pyrrolidine (Bradbury et al., 2005a). Betaine aldehyde dehydrogenase plays an important role in the biosynthesis of 2-acetyl-1-pyrrolidine, but how does betaine aldehyde dehydrogenase play its role in the synthesis of 2-acetyl-1-pyrrolidine, and whether other substances are involved in the regulation and control process are still unclear, thus further study is still needed.

Gamma aminobutyral as the precursor of 2-acetyl-1-pyrroline, may play a key role in the biosynthesis of 2-acetyl-1-pyrroline. In the fragrant rice varieties, the loss of the function of Badh2 protein may lead to the accumulation of gamma aminobutyral in the body and the transformation of gamma aminobutyral to 1-pyrroline, and the final synthesis of a large number of 2-acetyl-1-pyrrolines (Shan et al., 2015). In non-aromatic rice varieties, Badh2 protein has the catalytic activity of betaine aldehyde dehydrogenase, which may convert gamma aminobutyric aldehyde into gamma aminobutyric acid in rice grain, while inhibiting the synthesis of 1-pyrrolidine (2-AP precursor), resulting in the failure to synthesize 2-AP (Peng et al., 2017a) (Figure 1). In rice, ornithine and proline could be used as precursors for the synthesis of gamma aminobutyral. The regulatory network of this synthesis process and the regulatory relationship between them and betaine aldehyde dehydrogenase are not yet clear. The complex regulatory relationship between ornithine, proline, gamma aminobutyral and 1-pyrrolidine still needs further research. 


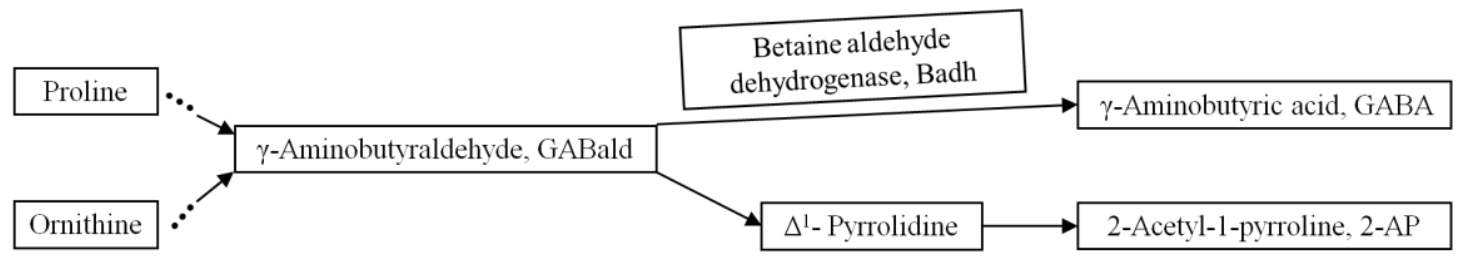

Figure 1. Possible synthesis pathway of 2-acetyl-1-pyrroline (2-AP) in rice

By comparison and analysis of the sequencing results of aroma gene in rice, most researchers believed that the loss of the second or seventh exon fragments of the Badh2 gene leads to a large accumulation of 2-AP (Kovach et al., 2009), and the fragrant is produced. In fact, the 2-AP content of some rice varieties is higher, but there is no Badh2 allele, which suggests that there may be other non Badh2 alleles that could also cause fragrant (Amarawathi et al., 2008). Most researchers pay attention to the difference exons between aromatic and nonaromatic rice varieties, in addition to the exon of gene in eukaryote, intron also play an important role in gene expression and regulation (Fu et al., 1995; Jeon et al., 2000). By sequencing the Badh2 in aromatic rice, the results showed that there was no mutation in the coding chain of the aromatic rice, neither of the seventh exon mutation nor the second exon mutation type, but the nucleotide sequence in the second and fourth intron region of the Badh2 gene had been mutated (Xu et al., 2011). There were 86 aromatic rice among the 323 rice germplasm resources, of which 80 were mutational types of seventh exon (Zhang et al., 2015). Further, the Badh2 gene of the other 6 aromatic rice germplasms was cloned and sequenced, the results showed that the Badh2 gene sequence from the 6 aromatic rice varieties was complete. Therefore, the fragrant characters of rice grain may also be regulated by other genes or introns.

\section{Development of Functional Markers of Rice Aroma Genes}

Since the Badh2 gene was isolated and cloned, more than a dozen mutation sites have been found in Badh2 (Kovach et al., 2009; Shao et al., 2013; He and Park, 2015, He et al., 2015), and a series of molecular markers are designed for these loci, which could be used for the identification of aroma gene, the selection of different aromatic rice varieties and the cultivation of new varieties of aromatic rice. Bradbury et al (2005b) used the Badh2 gene to have 8 bp deletion and 3 SNPs in seventh exon, and primers were designed for PCR amplification to identify whether the Badh2 allele is a type of aromatic rice. Then, new molecular markers YY5-YY8 were designed for the rapid detection and analysis of aromatic rice (Yan et al., 2015). By sequenced 24 aromatic rice varieties and 10 non-aromatic rice varieties, Shi et al (2008) found that there had 18 bp deletion and 3 SNPs mutation sites at seventh exon of the Badh2 in 12 aromatic rice varieties. In addition, a new Badh2 allele with no biological function was also found. The allele had the same mutation at exon 7, but a 7-bp deletion site was found at exon 2. For these variant regions of two exons, multiple pairs of molecular markers were designed for PCR detection analysis (Shi et al., 2008). Subsequently, in the detection of Badh2 gene mutations at exon 7 and exon 2, the primer design was simplified, and only one pair of primers was needed for detection aroma gene by molecular marker (Wang F et al., 2008; Wang J et al., 2008). Through gene sequencing and sequence analysis, it was found that there might be a loss of $803 \mathrm{bp}$ between the fourth and fifth exons of the Badh2 gene, and one marker FMbadh2-E4-5 was developed to detect the deletion of the new site (Shao et al., 2011). In the study of aromatic rice varieties, the presence of a single-nucleotide mutation at exon 13 of the Badh2 gene resulted in the generation of aromas in rice grain, and the mutation site was located at the splice site of the intron and exon. At this point, a new molecular marker was also designed (Ootsuka et al., 2014). According to the sequencing analysis of 295 different rice varieties, some aromatic rice varieties have a 3 bp deletion at the 12th exon and a 3 bp insertion at the 13th exon of Badh2 gene. Thus the functional molecular marker FME12-3 was designed and verified using two $\mathrm{F}_{2}$ genetic groups (He and Park, 2015). The development of a series of molecular markers of aroma gene has brought great convenience for the identification of rice aroma gene, screening of different aromatic rice varieties, and cultivation of new aromatic rice varieties. At the same time, these molecular markers will speed up the process of genetic breeding, popularization and application of aromatic rice. 
Table 1. Development of functional markers for Badh2 gene in rice (He and Park, 2015)

\begin{tabular}{llll}
\hline Functional markers & Primer sequence $\left(5^{\prime}-3^{\prime}\right)$ & $\begin{array}{l}\text { Annealing } \\
\text { temperature }\left({ }^{\circ} \mathrm{C}\right)\end{array}$ & $\begin{array}{l}\text { PCR production size (bp) } \\
\text { Non-fragrant/ fragrant }\end{array}$ \\
\hline FMU1-2 & $\begin{array}{l}\text { F: TCCCACCACCACTCCACA } \\
\text { R: ACGAAGAGCTGCCGCTGC }\end{array}$ & 61 & $163 / 160$ \\
FME2-7 & $\begin{array}{l}\text { F: ACGAAGAGCTGCCGCTGC } \\
\text { R: GCGATTGCGCGGAGGTACT }\end{array}$ & 61 & $78 / 71$ \\
FME7 & F: TCCTGTAATCATGTATACCC & 50 & $151 / 143$ \\
FME12-3 & $\begin{array}{l}\text { R: AATTTGGAAACAAACCTT } \\
\text { F: TTGGTCCAGTGCTCTGTGTG }\end{array}$ & 58 & $192 / 189$ \\
FME13 & $\begin{array}{l}\text { R: GCACCAGCCAGACCATAAC } \\
\text { F: TTGGTCCAGTGCTCTGTGTG } \\
\text { R: GCACCAGCCAGACCATAAC }\end{array}$ & 58 & $192 / 195$ \\
& $\begin{array}{l}\text { F: TCGATGCCGGAATTATCTGGGTGA } \\
\text { R: TCCCCACGGCTCATCGGAGG }\end{array}$ & 61 & $60,205 / 266$ \\
\hline
\end{tabular}

At present, there are at least 17 mutation sites have been discovered in the Badh2 gene, and these sites are located in the 5'-UTR region, exon 1, exon 1 and intron 1 junction, exons 2, exons 4 and 5, exons 7, 8, 10, 12, 13 and 14 of the Badh2 gene (He and Park, 2015). For these mutant loci, many pairs of molecular markers have been designed at the first exon, intron 1, exon 2, 4, 5, 7, 12, 13 and 14 of the Badh2 gene, which could also be used to identify the mutation type of the Badh2 gene (Bradbury et al., 2005a, 2005b; Shi et al., 2008; Kovach et al., 2009; Shao et al., 2011; Ootsuka et al., 2014; He and Park, 2015). There are also multiple variant sites in the exons 1, 2 and 10 of the Badh2 gene, but there is no direct correlation between them and the aroma of rice, this indicates that most of these mutations are synonymous mutations, or the mutations that change the sequence of Badh2 protein do not affect the function of Badh2 protein. Based on the above molecular markers, six functional markers of rice aroma gene were further developed (Table 1) and verified by segregating populations (Shi et al., 2008; Kovach et al., 2009; Ootsuka et al., 2014; He and Park, 2015; Peng et al., 2017b). Among them, the functional marker FMU1-2 could not only detect the 8 bp deletion mutation of Badh2 gene in the 7th exon, but also could detect whether there is an 8 bp deletion in the 5'-UTR region of Badh2 gene. The functional markers FME2-7, FME7, FME12-3, FME13, and FME14 were used to identify the mutation types of the fragrant gene in the exons 2, 7, 12, 13, and 14 of Badh2, respectively. The functional marker FME14 belongs to the cleaved amplified polymorphic sequence, and the detection of PCR products requires the use of restriction endonuclease $B s l$ I. Therefore, the development of these functional markers of rice aroma gene provides an accurate, rapid and effective method for molecular breeding of aromatic rice.

\section{Application of Aroma Genes in Rice Genetics and Breeding}

At present, the major techniques in rice breeding are still conventional cross-breeding, and for aromatic rice, it is time-consuming and laborious to cultivate new varieties using the traditional breeding methods (Shan et al., 2015). Since the aroma gene was mainly controlled by a recessive gene, the traditional breeding must first introduce the Badh2 mutant gene into the existing elite varieties through hybridization and backcrossing, and then screen the individuals in the offspring population, and it is difficult to quickly identify the process at the seedling stage. However, rice breeders in China have done a lot of researches on the cultivation of high-quality, high-yield, multi-resistance fragrant rice varieties, and screened a series of aromatic rice restorer lines, sterile lines, and new hybrid combinations (Huang et al., 2006 Hou et al., 2007; Liu et al., 2008; Jiang et al., 2008). With the development of molecular markers, especially the functional markers of Badh2 gene, molecular marker assisted selection has been widely used in rice genetics and breeding, which has greatly accelerated the process of screening and breeding of new varieties of aromatic rice, and many varieties of aromatic rice have been approved and have been widely used in production.

Early studies found that molecular markers closely linked to the frg gene (eg, RG28, SCU015RM, and RSP04) could distinguish between aromatic rice and non-aromatic rice (Garland et al., 2000; Cordeiro et al., 2002; Jin et al., 2003). With the further study of the function of the Badh2 gene, a series of specific primers (functional markers) were designed for the interior of the Badh2 gene for the screening of fragrant gene and the breeding restoration lines of aromatic rice (Bradbury et al., 2005b; Shi et al., 2008; Wang F et al., 2008; He and Park, 2015; Yan et al., 2015; Xu et al., 2015; Du et al., 2009). In addition, transgenic technology is also applied and promoted in the cultivation of new aromatic rice varieties (Niu et al., 2008; Chen et al., 2012). The utilization of 
RNAi mediated Badh2 gene silencing could also transform non-aromatic into aromatic rice varieties (Chen et al., 2012; Peng et al., 2017a), but this technique often does not completely inhibit the expression of Badh2 gene and needs to be screened in a large number of transgenic progeny plants. At the same time, the use of RNAi mediated transgenic technology to cultivate new aromatic rice varieties also faced with the risk assessment of late transgenic and strict supervision, and the promotion and application of new varieties of transgenic rice are still faced with many problems.

In recent years, genome editing technology has developed rapidly, including transcriptional activator effect factor nuclease technology, zinc finger nuclease technology and cluster law interval short palindromic repetition technology have been applied to crop genetics and breeding (Voytas and Gao, 2014). Any insertion, deletion or replacement of Badh2 gene will lead to premature termination codon or encoded amino acid change or even non coding corresponding Badh2 protein in rice, which could make non- aromatic rice produce fragrance (Bradbury et al., 2005a; Shi et al., 2008; Kovach et al., 2009). Therefore, the loss function of Badh2 gene could promote the synthesis and accumulation of 2-AP, and it is conceivable that any mutation that causes the loss of Badh2 gene function will lead to the emergence of one new aroma gene. Then, using TALEN technology to knock out the Badh2 gene, one non-aromatic rice variety could be transformed into aromatic rice varieties (Shan et al., 2013), and the TALEN technology could also be used to create a genetically homozygous mutant of aromatic rice plant (Shan et al., 2015). Thus, the TALEN technology could be used to knock out the Badh2 gene in non-aromatic rice (Shan et al., 2015; Birla et al., 2017), and quickly produce the corresponding aromatic rice, which greatly accelerates the breeding process of the new varieties of high quality and high yield rice.

\section{Prospect of the Application of Aroma Gene in Rice Breeding}

Fragrance is one of the most important traits in rice genetics and breeding, and the consumption demand of high-quality rice will continue to increase. Therefore, the breeding of new aromatic rice varieties and the research of aroma genes are attracting more and more attention from rice genetics and breeding scientists and plant scientists. With the rapid development of rice functional genome, it will become clear for the genetic basis, function and regulation of aroma genes in rice. In the last decade, the gene sequencing technology has developed rapidly, and a large number of rice varieties and aromatic rice germplasm resources from different sources have been sequenced, thus a series of mutation sites and alleles have been identified (He and Park, 2015, He et al., 2015). According to these mutation loci, the functional markers of aroma gene have also been developed, and have been widely applied in aroma gene screening and breeding of elite parents of hybrid rice. Although the aroma gene functional markers have been used for the breeding of aromatic rice restorer lines (Du Xueshu et al., 2009), and many aromatic rice varieties have been approved and widely used in production, the main problem in the process of aromatic rice genetics and breeding is still very few restorer lines with good scent type, which slows down the genetic breeding process of aromatic rice.

At present, not only the aroma gene is used to cultivate new aromatic rice varieties, but also the corresponding aroma genes are discovered in other crops and applied to the genetic breeding of major grain crops. For example, a 2 bp deletion in exon 10 of the $G m B A D H 2$ gene was located on chromosome 6 will cause the gene to prematurely terminate the translation process in Glycine max, thereby producing a fragrance (Juwattanasomran et al., 2011, 2012). 2-AP could be synthesized in large quantities if the $G m B A D H 2$ gene was silenced in soybean, and fragrant soybeans could be produced immediately (Arikit et al., 2011). At the same time, studies in sorghum found that the SbBADH2 gene is a recessive gene that controlled the fragrant in Sorghum (Yundaeng et al., 2013).The history of domestication of sorghum, rice, and soybeans is not the same, but the fragrant of the three crops is dominated by a single recessive gene (Murty et al., 1982; He and Park, 2015), in which the aroma gene is mutated and the production of these crop aromas is closely related, and the recessive gene controlling the fragrant have a certain degree of homology (Arikit et al., 2011). Although the loss of aroma gene in rice, sorghum and soybeans does not affect their survival, it will play an active role in drought conditions.

With the rapid development of genome editing technology, sequence-specific nucleases could be widely used for gene knockout of various plants, including the important crops such as rice, maize, wheat, barley and soybean (Li et al., 2012; Wendt et. al., 2013; Haun et al., 2014; Liang et al., 2014; Wang et al., 2014). Among them, TALEN technology has also been applied to the genetics and breeding of aromatic rice (Shan et al., 2013, 2015; Birla et al., 2017). These new techniques provide a new strategy for rice breeders to cultivate aromatic rice varieties. The utilization of SSNs (including TALEN, ZFN and CRISPR) for molecular design breeding is superior to the traditional breeding and genetically modified (RNAi or genetic engineering) breeding: (1) The target genes could be accurate edited. (2) No need for hybridization and backcross process, which will save a lot of time and convenience. (3) A single plant without screening markers can be obtained (Shan et al., 2015; Peng et al., 2017a). Therefore, there will be more and more new technologies applied to the genetic breeding of 
aromatic rice, such as TALEN technology, ZFN technology, and CRISPR technology, and these new technologies will accelerate the cultivation of new aromatic rice varieties with high-quality, high-yield and multiple resistance.

\section{Acknowledgments}

This work was financially supported by National Natural Science Foundation of China (U1604110, U1404319, 31600992), Key Project of Science and Technology in Henan Province (182102110442, 152102110100, 152102110036), Students Innovation and Training Program of Institution of Higher Learning in Henan Province (201710477018Y); Nanhu Scholars Program for Young Scholars of XYNU (2016054), Scientific Research Innovation Project for Postgraduate of XYNU(2017KYJJ44); Major Science and Technology Project in Henan Province (121100110200) and Institute for Conservation and Utilization of Agro-bioresources in Dabie Mountains.

\section{References}

Ahn, S. N., Bollich, C. N., \& Tanksley, S. D. (1992). RFLP tagging of a gene for aroma in rice. Theor Appl Genet, 84, 825-828. https://doi.org/ 10.1007/BF00227391

Amarawathi, Y., Singh, R., Singh, A. K., Singh, V. P., Mohapatra, T., Sharma, T. R., \& Singh, N. K. (2008). Mapping of quantitative trait loci for basmati quality traits in rice (Oryza sativa L.). Mol Breed, 21, 49-65. https://doi.org/ 10.1007/s11032-007-9108-8

Arikit, S., Yoshihashi, T., Wanchana, S., Uyen, T. T., Huong, N. T., Wongpornchai, S., \& Vanavichit, A. (2011). Deficiency in the amino aldehyde dehydrogenase encoded by GmAMADH2, the homologue of rice Os2AP, enhances 2-acetyl-1-pyrroline biosynthesis in soybeans (Glycine max L.). Plant Biotechnol J., 9, 75-87. https://doi.org/10.1111/j.1467-7652.2010.00533.x

Bai, X. G., Cheng, Z. Q., Lin, Z. L., Lv, G. L., \& Huang, X. Q. (2009). Comparison of genetic diversity between aromatic rice and non aromatic rice in Yunnan. Anhui Agricultural Sciences, 37, 2404-2406. https://doi.org/10.13989/j.cnki.0517-6611.2009.06.089

Birla, D. S., Malik, K., Sainger, M., Chaudhary, D., Jaiwal, R., \& Jaiwal, P. K. (2017). Progress and challenges in improving the nutritional quality of rice (Oryza sativa L.). Crit Rev Food Sci Nutr., 57, 2455-2481, https://doi.org/10.1080/10408398.2015.1084992

Bradbury, L. M. T., Fitzgerald, T. L., Henry, R. J., Jin, Q. S., \& Waters, D. L. E. (2005a). The gene for fragrance in rice. Plant Biotechnol J., 3, 363-370. http://dx.doi.org/10.1111/j.1467-7652.2005. 00131.x

Bradbury, L. M. T., Henry, R. J., Jin, Q., Reinke, R. F., \& Waters, D. L. E. (2005b). A perfect marker for fragrance genotyping in rice. Mol Breed, 16, 279-283. https://doi.org/10.1007/s11032-005-0776-y

Bradbury, L. M. T., Gillies, S. A., Brushett, D. J., Waters, D. L. E., \& Henry, R. J. (2008). Inactivation of an aminoaldehyde dehydrogenase is responsible for fragrance in rice. Plant Mol Biol., 68, 439-449. https://doi.org/ 10.1007/s11103-008-9381-x

Chen, M. L., Wei, X. J., Shao, G. N., Tang, S. Q., Luo, J., \& Hu, P. S. (2012). Fragrance of the rice grain achieved via artificial microRNA-induced down-regulation of OsBADH2. Plant Breed, 131, 584-590. https://doi.org/10.1111/j.1439-0523.2012.01989.x

Chen, S.H., Wu, J., Yang, Y., Shi, W.W., Xu, M.L. (2006). The fgr gene responsible for rice fragrance was restricted within 69 kb. Plant Sci 171, 505-514. https://doi.org/10.1016/j.plantsci.2006. 05.013

Chen, S. H., Yang, Y., Shi, W. W., Ji, Q., He, F., Zhang, Z. D., Cheng, Z. K., Liu, X. N., \& Xu, M. L. (2008). Badh2, encoding betaine aldehyde dehydrogenase, inhibits the biosynthesis of 2-Acetyl-1-Pyrroline, a major component in rice fragrance. Plant Cell, 20, 1850-1861. https://10.1105/tpc.108.058917

Cordeiro, G. M., Christopher, M. J., Henry, R. J., \& Reinke, R. F. (2002). Identification of microsatellite markers for fragrance in rice by analysis of the rice genome sequence. Mol Breed, 9, 245-250. https://doi.org/10.1023/A:1020350725667

Daygon, V. D., Prakash, S., Calingacion, M., Riedel, A., Ovenden, B., Snell, P., Mitchell, J., \& Fitzgerald, M. (2016). Understanding the jasmine phenotype of rice through metabolite profiling and sensory evaluation. Metabolomics, 12, 63. https://doi.org/10.1007/s11306-016-0989-6

Dong, Y. J., Tsuzuki, E., Terao, H., Yosimura, A., \& Yasui, H. (2001a). Inheritance of aroma and identification of RELP markers linked to aroma genes in two rice cultivars (Oryza sativa L.). Bull Fac Agric., 48, 59-65. 
Dong, Y. J., Tsuzuki, E., \& Terao, H. (2001b). Trisomic genetic analysis of aroma in three japanese native rice varieties (Qryza sativa L.). Euphytica, 117, 191-196. https://doi.org/10.1023/A: 1026502115436

Du, X. C., Xia, M. Y., Li, J. B., Wan, B. L., Zha, Z. P., \& Qi, H. X. (2009). Molecular marker-assisted selection for breeding of restoring lines in aroma rice. Journal of Huazhong Agricultural University, 28, 651-654. https://doi.org/10.3321/j.issn:1000-2421.2009.06.002

Fitzgerald, M. A., Sackville, H. N. R., Calingacion, M. N., Verhoeven, H. A., \& Butardo, V. M. (2008). Is there a second fragrance gene in rice? Plant Biotechnol J., 6, 416-423. https://doi.org/10.1111/j.1467-7652.2008.00327.x

Fu, H. Y., Kim, S. Y., \& Park, W. D. (1995). High-level tuber expression and sucrose inducibility of a potato Sus4 sucrose synthase gene require 5' and $3^{\prime}$ flanking sequences and the leader intron. Plant Cell, 7 , 1387-1394. https://doi.org/ 10.1105/tpc.7.9.1387

Garland, S., Lewin, L., Blakeney, A., Reinke, R., \& Henry, R. (2000). PCR-based molecular markers for the fragrance gene in rice (Oryza satlva. L.). Theor Appl Genet, 101, 364-371. https://doi.org/10.1007/s001220051492

Goufo, P., Falco, V., Brites, C., Wessel, D. F., Kratz, S., Rosa, E. A. S., Carranca, C., \& Trindade, H. (2014). Effect of elevated carbon dioxide concentration on rice quality: nutritive value, color, milling, cooking, and eating qualities. Cereal Chem J., 91, 513-521. https://doi.org/10.1094/CCHEM- 12-13-0256-R

Halford, N. G., Curtis, T. Y., Chen, Z. W., \& Huang, J. H. (2014). Effects of abiotic stress and crop management on cereal grain composition: implications for food quality and safety. $J$ Exp Bot., 66, 1145-1156. https://doi.org/10.1093/jxb/eru473

Haun, W., Coffman, A., Clasen, B. M., Demorest, Z. L., Lowy, A., Ray, E., ... Zhang, F. (2014). Improved soybean oil quality by targeted mutagenesis of the fatty acid desaturase 2 gene family. Plant Biotechnol J., 12, 934-940. https://doi.10.1111/pbi.12201

Huang, T. X., Jiang, W. Q., You, Q. R., Zhou, S. Q., Liu, D. H., Xie, D. R., \& Qiu, H. M. (2006). Breeding and utilization of restorer line Daolixiang 15 of indica rice. Fujian Journal of Agricultural Sciences, 21, 83-88. https://doi.org/10.19303/j.issn.1008-0384.2006.02.001

He, Q., \& Park, Y. J. (2015). Discovery of a novel fragrant allele and development of functional markers for fragrance in rice. Mol Breed, 35, 217. https://doi.org/ 10.1007/s11032-015-0412-4

He, Q., Yu, J., Kim, T. S., Cho, Y. H., Lee, Y. S., \& Park, Y. J. (2015). Resequencing reveals different domestication rate for $B A D H 1$ and $B A D H 2$ in rice (Oryza sativa). PLoS One, 10, e0134801. https://doi.org/10.1371/journal.pone.0134801

Jeon, J. S., Lee, S., Jung, K. H., Jun, S. H., Kim, C., \& An, G. (2000). Tissue-preferential expression of a rice $\alpha$-tubulin gene, OsTubA1, mediated by the first intron. Plant Physiol., 12, 1005-1014. https://doi.org/10.1104/pp.123.3.1005

Jiang, Q. S., Lin, G., Zhao, D. M., Li, Y. W., He, B., \& Wang, F. (2008). Characteristics and utilization of aromatic high quality sterile line Yixiang 1A. Chinese Rice, 2, 35-37. https://doi.org/10.3969/j.issn.1006-8082.2008.02.011

Jin, Q. S., Qin, B. Q., Yan, W. C., \& Luo, R. B. (1995). Tagging of a gene for aroma in rice by RAPD and RFLP(I). Acta Agric Zhejiangensis, 7, 439-442.

Jin, Q. S., Qin, B. Q., Yan, W. C., \& Luo, R. B. (1996). Tagging of a gene for aroma in rice by RAPD and RFLP(II). Acta Agric Zhejiangensis, 8, 19-23.

Jin, Q. S., Waters, D., Cordeiro, G. M., Henry, R. J., \& Reinke, R. F. (2003). A single nucleotide polymorphism (SNP) marker linked to the fragrance gene in rice (Oryza sativa L.). Plant Sci., 165, 359-364. https://doi.org/10.3969/j.issn.1672-416X.2008.06.030

Juwattanasomran, R., Somta, P., Chankaew, S., Shimizu, T., Wongpornchai, S., Kaga, A., \& Srinives, P. (2011). A SNP in GmBADH2 gene associates with fragrance in vegetable soybean variety "Kaori" and SNAP marker development for the fragrance. Theor Appl Genet, 122, 533-541. https://doi.org/10.1007/s00122-010-1467-6

Juwattanasomran, R., Somta, P., Kaga, A., Chankaew, S., Shimizu, T., Sorajjapinun, W., \& Srinives, P. (2012). Identification of a new fragrance allele in soybean and development of its functional marker. Mol Breed, 29, 13-21. https://doi.org/10.1007/s11032-010-9523-0 
Kuang, H. C., Zeng, Z. M., Liu, G. M., Luo, J. T., Wen, S. S., Chen, G. Z., \& Yang, Y. (2007). Characters and high-yield breeding techniques of the high quality, aromatic triline sterile line Luxiang 91A. Chinese Rice, 4 , 28-29. https://doi.org/10.3969/j.issn.1006-8082.2007.04.011

Kovach, M. J., Calingacion, M. N., Fitzgerald, M. A., \& McCouch, S. R. (2009). The origin and evolution of fragrance in rice (Oryza sativa L.). Proc Natl Acad Sci USA, 106, 14444-14449. https://doi.org/10.1073/pnas.0904077106

Kusano, M., Yang, Z. G., Okazaki, Y., Nakabayashi, R., Fukushima, A., \& Saito, K. (2015). Using metabolomic approaches to explore chemical diversity in rice. Mol Plant, 8, 58-67. https://doi.org/10.1016/j.molp.2014.11.010

Li, S. J., Gao, J., Li, J. Y., Wang, Y. H. (2015). Research Progress on the regulation of rice tillering by single legged gold lactone. Journal of plant, 50, 539-548. https://doi.org/ 10.11983/CBB15076

Li, T., Liu, B., Spalding, M. H., Weeks, D. P., \& Yang, B. (2012). High-efficiency TALEN-based gene editing produces disease-resistant rice. Nat Biotechnol., 30, 390-392. https://doi.org /10.1038/nbt.2199

Liang, Z., Zhang, K., Chen, K. L., \& Gao, C. X. (2014). Targeted mutagenesis in Zea mays using TALENs and the CRISPR/Cas system. J Genet Genom, 41, 63-68. https://doi.org/10.1016/j.jgg. 2013.12.001

Liu, H. L., Zhang, Y., Zou, D. T., Zhao, H. W., Wang, J. G., \& Sun, J. (2014). Screening of aromatic rice germplasm resources and genetic study of aroma genes. Crop Magazine, 6, 21-26. https://doi.org/10.16035/j.issn.1001-7283.2014.06.004

Liu, G. C., Lu, X. J., Ren, G. J., Gao, F. Y., Li, Z. H., Ren, M. X., \& Tang, J. (2008). Breeding and cultivation techniques of a new hybrid rice combination Chuanxiangyou 425. Chinese Rice, 2, 42-43. https://doi.org/10.3969/j.issn.1006-8082.2008.02.015

Lorieux, M., Petrov, M., Huang, N., Guiderdoni, E., Ghesquière, A. (1996). Aroma in rice: genetic analysis of a quantitative trait. Theor Appl Genet 93, 1145-1151. https://doi.org /10.1007/BF00230138

Mahattanatawee, K., \& Rouseff, R. L. (2014). Comparison of aroma active and sulfur volatiles in three fragrant rice cultivars using GC-Olfactometry and GC-PFPD. Food Chem., 154, 1-6. https://doi.org/10.1016/j.foodchem.2013.12.105

Mathure, S. V., Jawali, N., Thengane, R. J., \& Nadaf, A. B. (2014). Comparative quantitative analysis of headspace volatiles and their association with BADH2 marker in non-basmati scented, basmati and non-scented rice (Oryza sativa L.) cultivars of india. Food Chem., 142, 383-391. https://doi.org/10.1016/j.foodchem.2013.07.066

Murty, D. S., Nicodemus, K. D., \& House, L. R. (1982). Inheritance of basmati and dimpled seed in sorghum. Crop Sci., 22, 1080-1082. https://doi.org/10.2135/cropsci1982.0011183X 002200050046x

Myint, K. M., Arikit, S., Wanchana, S., Yoshihashi, T., Choowongkomon, K., \& Vanavichit, A. (2012). A PCR-based marker for a locus conferring the aroma in Myanmar rice (Oryza sativa L.). Theor Appl Genet, 125, 887-896. https://doi.org/10.1007/s00122-012-1880-0

Niu, X. L., Tang, W., Huang, W. Z., Ren, G. J., Wang, Q. L., Luo, D., ... Liu, Y. S. (2008). RNAi-directed downregulation of $O s B A D H 2$ results in aroma (2-acetyl-1-pyrroline) production in rice (Oryza sativa L.). BMC Plant Biol., 8, 100. https://doi.org/10.1186/1471-2229-8-100

Ootsuka, K., Takahashi, I., Tanaka, K., Itani, T., Tabuchi, H., Yoshihashi, T., Tonouchi, A., \& Ishikawa, R. (2014). Genetic polymorphisms in japanese fragrant landraces and novel fragrant allele domesticated in northern Japan. Breed Sci., 64, 115-124. https://doi.org /10.1270/jsbbs.64.115

Paule, C. M., \& Powers, J. J. (1989). Sensory and chemical examination of aromatic and nonaromatic rices. $J$ Food Sci., 54, 343-346. https://doi.org/10.1111/j.1365-2621.1989.tb03076.x

Peng, B., Pang, R. H., Sun, Y. F., Geng, L. P., Song, X. H., Li, H. L., ... Song, S. Z. (2016a). Chalkiness Traits of aromatic rice endosperm and scanning electron microscopic observation. Southern J Agricul Sci., 47, 1635-1641. https://doi.org/10.3969/jissn. 2095-1191.2016.10.1635

Peng, B., Kong, H. L., Li, Y. B., Wang, L. Q., Zhong, M., Sun, L., ... He, Y. Q. (2014a). OsAAP6 functions as an important regulator of grain protein content and nutritional quality in rice. Nat Commun., 5, 4847. https://doi.org/10.1038/ncomms5847

Peng, B., Kong, H. L., Pang, R. H., Sun, Y. F., Song, X. H., Li, H. L., ...Song, S. Z. (2017b). Detection and 
application of functional markers of Badh2 gene from different fragrant rice varieties in Southern Henan. Southwest China Journal of Agricultural Sciences, 30, 1693-1699.

https://doi.org/10.16213/j.cnki.scjas. 2017. 8.001

Peng, B., Sun, Y. F., Chen, B. Y., Sun, R. M., Kong, D. Y., Pang, R. H., ... Song, S. Z. (2017a). Research progress of fragrance gene and its application in rice breeding. Chin Bull Bot., 52, 797-807.

https://doi.org/10.11983/CBB16197

Peng, B., Sun, Y. F., Li, Q. R., Li, D., Pang, R. H., Zhou, Q. Y., ... Song, S. Z. (2016b). Progress in genetic research of chalkiness traits in rice. Journal of Xinyang Normal University (Natural Science Edition), 29, 304-312. https://doi.org/10.3969/j.issn.1003-0972.2016.02.035

Peng, B., Wang, L. Q., Fan, C. C., Jiang, G. H., Luo, L. J., Li, Y. B., \& He, Y. Q. (2014b). Comparative mapping of chalkiness components in rice using five populations across two environments. BMC Genet., 15, 49. https://doi.org/10.1186/1471-2156-15-49

Prathepha, P. (2009). The fragrance ( $f g r)$ gene in natural populations of wild rice (Oryza rufipogon Griff.). Genet Resour Crop Evol., 56, 13-18. https://doi.org/10.1007/s10722-008-9337-7

Schieberle, P. (1990). The role of free amino acids present in yeast as precursors of the odorants 2-acetyl-1-pyrroline and 2-acetyltetrahydropyridine in wheat bread crust. Z Lebensm Unters Forsch, 191, 206-209. https://doi.org/10.1007/BF01197621

Shan, Q. W., Wang, Y. P., Chen, K. L., Liang, Z., Li, J., Zhang, Y., ... Gao, C. X. (2013). Rapid and efficient gene modification in rice and Brachypodium using TALENs. Mol Plant, 6, 1365-1368. https://doi.org/10.1093/mp/sss162

Shan, Q. W., Zhang, Y., Chen, K. L., Zhang, K., \& Gao, C. X. (2015). Creation of fragrant rice by targeted knockout of the $O s B A D H 2$ gene using TALEN technology. Plant Biotechnol J., 13, 791-800. https://doi.org/10.1111/pbi.12312

Shao, G. N., Tang, A., Tang, S. Q., Luo, J., Jiao, G. A., Wu, J. L., \& Hu, P. S. (2011). A new deletion mutation of fragrant gene and the development of three molecular markers for fragrance in rice. Plant Breed, 130, 172-176. https://doi.org/10.1111/j.1439-0523.2009.01764.x

Shao, G. N., Tang, S. Q., Chen, M. L., Wei, X. J., He, J. W., Luo, J., ... Hu, P. S. (2013). Haplotype variation at Badh2, the gene determining fragrance in rice. Genomics, 101, 157-162. https://doi.org/10.1016/j.ygeno.2012.11.010

Shi, W. W., Yang, Y., Chen, S. H., \& Xu, M. L. (2008). Discovery of a new fragrance allele and the development of functional markers for the breeding of fragrant rice varieties. Mol Breed, 22, 185-192. https://doi.org/10.1007/s11032-008-9165-7

Shi, Y. Q., Zhao, G. C., Xu, X. L., \& Li, J. Y. (2014). Discovery of a new fragrance allele and development of functional markers for identifying diverse fragrant genotypes in rice. Mol Breed, 33, 701-708. https://doi.org/10.1007/s11032-013-9986-x

Stocker, B. D., Roth, R., Joos, F., Spahni, R., Steinacher, M., Zaehle, S., Bouwman, L., Ri, X., \& Prentice, I. C. (2013). Multiple greenhouse-gas feedbacks from the land biosphere under future climate change scenarios. Nat Clim Change, 3, 666-672. https://doi.org /10.1038/nclimate1864

Tang, A., Shao, G. N., \& Hu, P. S. (2009). Advances in research on rice aroma genes. Chinese Rice, 4, 1-4. https://doi.org/10.3969/j.issn.1006-8082.2009.04.001

Tian, Z. X., Qian, Q., Liu, Q. Q., Yan, M. X., Liu, X. F., Yan, C. J., ... Li, J. Y. (2009). Allelic diversities in rice starch biosynthesis lead to a diverse array of rice eating and cooking qualities. Proc Natl Acad Sci USA, 106, 21760-21765. https://doi.org/10.1073/pnas.0912396106

Trossat, C., Rathinasabapathi, B., \& Hanson, A. D. (1997). Transgenically expressed betaine aldehyde dehydrogenase efficiently catalyzes oxidation of dimethylsulfoniopropionaldehyde and [omega]-aminoaldehydes. Plant Physiol. 113, 1457-1461. https://doi.org/10.1104/pp.113.4.1457

Tsuzuki, E., \& Shimokawa, E. (1990). Inheritance of aroma in rice. Euphytica, 46, 157-159. https://doi.org/10.1007/BF00022309

Voytas, D. F., \& Gao, C. X. (2014). Precision genome engineering and agriculture: opportunities and regulatory challenges. PLoS Biol., 12, e1001877. https://doi.org /10.1371/journal.pbio.1001877 
Wanchana, S., Kamolsukyunyong, W., Ruengphayak, S., Toojinda, T., Tragoonrung, S., \& Vanavichit, A. (2005). A rapid construction of a physical contig across a $4.5 \mathrm{cM}$ region for rice grain aroma facilitates marker enrichment for positional cloning. Sci Asia, 31, 299-306. https://doi.org/10.2306/scienceasia1513-1874.2005.31.299

Wang, F., Li, J. H., Liu, W. G., Liao, Y. L., Zhu, M. S., Liu, Z. R., Huang, H. J., \& Huang, D. J. (2008). Development of a rice flavor gene functional marker. Chinese Rice Science, 22, 347-352. https://doi.org/10.16819/j.1001-7216.2008.04.003

Wang, J., Yang, J., Chen, Z. D., \& Zhong, W. G. (2008). Development and application of rice fragrant rice gene marker. Molecular Plant Breeding, 6, 1209-1212. https://doi.org/10.3969/j.issn.1672- 416X.2008.06.030

Wang, Y. P., Cheng, X., Shan, Q. W., Zhang, Y., Liu, J. X., Gao, C. X., \& Qiu, J. L. (2014). Simultaneous editing of three homoeoalleles in hexaploid bread wheat confers heritable resistance to powdery mildew. Nat Biotechnol, 32, 947-951. https://doi.org/10.1038/nbt.2969

Wendt, T., Holm, P., Starker, C., Christian, M., Voytas, D., Brinch-Pedersen, H., \& Holme, I. B. (2013). TAL effector nucleases induce mutations at a pre-selected location in the genome of primary barley transformants. Plant Mol Biol., 83, 279-285. https://doi.org/10.1007/s11103-013-0078-4

Yoshihashi, T., Huong, N. T. T., \& Inatomi, H. (2002). Precursors of 2-acetyl-1-pyrroline, a potent flavor compound of an aromatic rice variety. J Agric Food Chem., 50, 2001-2004. https://doi.org/10.1021/jf011268s

Xu, C. W., \& MO, H. D. (1995). Quality-quantity analysis of endosperm traits. Journal of Jiangsu Agricultural College, 16, 9-13. https://doi.org/10.16872/j.cnki.1671-4652.1995.01.003

Xu, X. L., Zhao, G. C., \& Li, J. E. (2011). Analysis of betaine aldehyde dehydrogenase 2 gene mutation in 24 aromatic rice cultivars and development of molecular markers. Journal of Plant Classification and Resources, 33, 667-673.

Xu, Y. F., Huang, J., Wang, Y. C., Wang, J., \& Li, J. E. (2015). Establishment of two molecular markers for screening rice Badh2-E2 type aromatic genes. Molecular Plant Breeding, 13, 2441-2445. https://doi.org/10.13271/j.mpb.013.002441

Yan, Y., Zhu, G. M., Zhang, L. X., Wan, C. Z., Cao, L. M., Zhao, Z. P., \& Wu, S. J. (2015). Development and application of rice flavor gene molecular markers. Northwestern Journal of Botany, 35, 269-274. https://doi.org/10.7606/j.issn.1000-4025.2015.02.0269

Yundaeng, C., Somta, P., Tangphatsornruang, S., Wongpornchai, S., \& Srinives, P. (2013). Gene discovery and functional marker development for fragrance in sorghum (Sorghum bicolor (L.) Moench). Theor Appl Genet., 126, 2897-2906. https://doi.org/10.1089/jmf.2013.0013

Zhang, J. L., Li, S. J., Li, J., Pu, S. H., Pu, Y. J., Zhang, L., ... Wen, J. C. (2015). Identification of the Badh2 locus of rice germplasm resources from different sources. Molecular Plant Breeding, 13, 727-733. https://doi.org/10.13271/j.mpb.013.000727

Zhang, T., Zhang, H. Y., Jiang, K. F., Xu, P. Z., Wang, X. D., Wu, X. J., \& Zheng, J. G. (2008). Fine mapping of rice flavor genes. Molecular Plant Breeding, 6, 1038-1044. https://doi.org/10.3969/j.issn.1672-416X.2008.06.002

Zhao, X. Q., \& Fitzgerald, M. (2013). Climate change: implications for the yield of edible rice. PLoS One, 8, e66218. https://10.1371/journal.pone.0066218

Zhao, Z. P., li, G., Wu, S. J., \& Lu, J. A. (2009). Research progress of aromatic rice. Shanghai Journal of Agricultural Sciences, 25(2), 110-114. https://doi.org/10.3969/j.issn.1000-3924.2009.02.024

\section{Copyrights}

Copyright for this article is retained by the author(s), with first publication rights granted to the journal.

This is an open-access article distributed under the terms and conditions of the Creative Commons Attribution license (http://creativecommons.org/licenses/by/4.0/). 